\title{
EMOTIONS, APPRAISALS, AND EMBODIED APPRAISALS
}

\author{
DAVID PINEDA \\ Departament de Filosofia \\ Facultat de Lletres \\ Universitat de Girona \\ david.pineda@udg.edu
}

\begin{abstract}
SUMMARY: Jesse Prinz's recent perceptual theory of emotion honors the central Jamesian claim that the emotion follows, and is actually caused by, the syndrome of bodily changes which are typical of emotional reactions. Prinz also thinks that emotions essentially involve appraisals of the object of emotion but, in the light of certain arguments supporting the central Jamesian claim, he concludes that these appraisals must be in any case embodied. In this paper, I will first raise three concerns with Prinz's view and, second, I will present an alternative, the multidimensional appraisal theory of emotion, and argue that this alternative can accommodate successfully the Jamesian arguments without any need to honor the central Jamesian claim.
\end{abstract}

KEY WORDS: emotion, appraisal theories, feeling theories, perceptual theories, phenomenology of emotion

RESUmen: La teoría perceptiva de las emociones que Jesse Prinz ha defendido recientemente mantiene la tesis jamesiana según la cual la emoción es un efecto causal del conjunto de cambios corporales que aparecen típicamente durante los episodios emotivos, y es, por tanto, posterior a dichos cambios. Prinz defiende también que las emociones encierran valoraciones del estímulo emotivo, pero a la vista de sus razones a favor de la tesis jamesiana, sostiene que tales valoraciones son corporeizadas. En este trabajo, en primer lugar presento tres objeciones a la teoría de Prinz y, en segundo lugar, ofrezco una teoría alternativa, la teoría valorativa multidimensional de las emociones. Mi argumento es que esta alternativa puede responder a los argumentos de Prinz sin necesidad de adoptar la tesis jamesiana.

PALABRAS CLAVE: emoción, teorías valorativas, teorías de las sensaciones, teorías perceptivas, fenomenología de las emociones

\section{Introduction}

Jesse Prinz has recently defended a perceptual theory about emotions according to which emotions involve embodied appraisals. His view honors the central Jamesian claim that the emotion follows, and is actually caused by, the syndrome of bodily changes which are typical of emotional reactions. Prinz also thinks that emotions essentially involve appraisals of the object of emotion but, in the light of certain arguments supporting the central Jamesian claim, he concludes that these appraisals must be in any case embodied. In this paper, after laying out the bare bones of Prinz's position, I will first raise three concerns with Prinz's view and, second, I will present an alternative, 
the multidimensional appraisal theory of emotion, and argue that this alternative can accommodate successfully the Jamesian arguments without any need to honor the central Jamesian claim. So my final conclusion will be that emotions are appraisals, but not embodied appraisals.

\section{Prinz's Theory}

In his book Gut Reactions (2004), Jesse Prinz has defended an original perceptual theory of emotion. Part of the originality and interest of the theory lies in the fact that it cleverly integrates elements of socalled judgmentalist or cognitive theories of emotions (Solomon 1976, 2003; Nussbaum 2001) into the overall framework of the James-Lange theory (James 1884), two main theoretical approaches to emotion often thought to be antagonistic. The theory is also compelling because it is argued for after a careful examination both of philosophical considerations and extant empirical studies about emotions.

Prinz's theory honors the central Jamesian claim. He argues that bodily changes frequently associated with emotions (facial expressions, vocal and musculo-skeletical changes, and changes in the Autonomous Nervous System and the Endocrine System) actually precede emotion rather than following it. James was then right to hold that bodily changes are causes of emotion and not effects thereof. Actually Prinz makes the orthodox Jamesian claim that emotions are perceptions of bodily changes. For future reference, let us state this central Jamesian claim in a more formal way:

(J) Bodily changes precede, and actually cause, emotions.

Prinz has offered three main reasons for claim (J). First, he simply accepts James" "subtraction argument", which is based on a wellknown thought experiment. According to James, if we fancy a strong emotion and abstract away from it all feelings of bodily disturbances what we are left with is definitely not an emotion. Prinz reads this thought experiment as showing that the phenomenology of emotion is exhausted by feelings of bodily changes. This is of course a conclusion which supports $(\mathrm{J})$. If emotions are caused by bodily changes, and are actually perceptions thereof, then it is only to be expected that the phenomenology of emotions is exhausted by feelings of bodily changes, since emotions would be essentially feelings of these bodily changes. Prinz also points out some recent empirical evidence as supporting the conclusions of James' thought experiment. Thus, according to a recent study when subjects report being experiencing 
a particular emotion there is a significant engagement of areas of the brain, such as the cingulate cortex, the hypothalamus, and certain somatosensory cortices and regions of the brain stem, which are known to build maps of the body informing about the current state of the organism (Damasio et al. 2000).

Second, Prinz accepts Robert Zajonc's view that emotion and cognition involve separate neuroanatomical structures. In Gut Reactions, Prinz mentions Joseph LeDoux's findings about fear (LeDoux 1996) as providing good evidence for this conclusion. LeDoux found out that fear responses to snake-like objects are entirely processed through subcortical regions of the brain. It seems that when the thalamus has the information that the stimulus might be a snake (the thalamus cannot make fine discriminations, the primary visual cortex is required for that task) it sends a signal not just to the primary visual cortex but to the amygdala as well. The amygdala is another very important subcortical structure which is known to orchestrate all by itself the sort of bodily changes typically involved in episodes of fear (Damasio 2010). As the amygdala gets activated, typical fear changes ensue and usually a withdrawal behavior follows quite quickly, before or just when the signal reaches the primary visual cortex. This is why one can sometimes find oneself stepping back from a coiled object at the same time one realizes it is not a snake but, say, a house pipe. Now assuming that subcortical brain regions do not implement tasks which require the use of concepts, LeDoux's evidence would then show that some fear responses occur without the mediation of cognitive states such as those that would be required for the sort of appraisals and evaluations postulated by cognitive theories such as Solomon's or Nussbaum's. Of course, LeDoux's evidence, by contrast, is entirely consistent with the Jamesian view that a state of fear is just the perception of the bodily changes orchestrated by the amygdala.

Third, Prinz also endorses the claim, which was already put forward by Karl Lange, that emotions can arise by direct physical induction. The administration of certain drugs, for instance, seems to have the power to change our emotional state. Consider as an example the ingestion of alcohol and its emotional effects. There seems to be also some evidence to the effect that voluntary acquisition of facial expressions characteristic of the expression of certain emotions actually gives rise to the corresponding emotion (Zajonc et al. 1989). This is again something which a Jamesian theory can account for perfectly well. While the explanation of the second sort of cases, voluntary acquisition of facial expressions of emotion, is quite straightforward, 
the explanation for the first cases would be that certain drugs have the power to provoke the sort of bodily changes the perception of which is the emotion.

These are then the three main reasons that, according to Prinz, should commit us with claim (J). In the last section of this paper I will address these three reasons and offer my responses to them. I will argue that, contrary to what Prinz thinks, they do not compel us to accept (J).

Now, although for these three reasons Prinz thinks that emotions follow bodily changes and are actually perceptions of these changes, his view is not entirely Jamesian. He claims that emotions are perceptions of bodily changes but they do not represent the bodily changes they perceive. Prinz introduces a subtle distinction between registering and representing to make that crucial point clearer. A mental state, he says, registers that which reliably causes it to be activated. Representing, on the other hand, is defined drawing on ideas of Dretske and Millikan: a mental state represents that which it has the function to carry information about. Or to put it in the concise terms that Prinz likes to use: a mental state represents that which it is set up to be set off by.

Now, according to Prinz, emotions are definitely not set up to carry information about bodily changes. This view, he thinks, cannot adequately explain why emotions were naturally selected as they conferred some sort of survival advantage. He argues that emotions are used to promote certain specific behaviors which become unintelligible if we assume that emotions represent bodily changes (2004, p. 59). For instance, in many cases fear compels us to run away from the eliciting stimulus, but to say that we run away because we feel that certain changes are taking place in our body makes little sense. In an interesting twist in the discussion between cognitivists and Jamesians, Prinz claims that emotions represent core relational themes. This is, surprisingly enough, a technical term directly borrowed from Richard Lazarus' cognitivist appraisal theory of emotion. Lazarus famously argued that an emotional episode starts when the stimulus is appraised by the organism according to several appraisal dimensions (more on this in the third section, where I introduce multidimensional appraisal theories). Moreover, an emotion is type individuated, according to Lazarus, by the results of the appraisal process in each of these dimensions. The notion of core relational theme was introduced by Lazarus meaning a sort of summary of the results obtained for the several appraisal dimensions. Therefore, for 
each emotion type (fear, anger, guilt, etc.) we will find one individuating core relational theme. For instance, in the case of fear, the core relational theme, according to Lazarus, is "facing a danger" (1991, p. 122). ${ }^{1}$

As Prinz rightly stresses, core relational themes gloss the bearing of a stimulus on the well-being of the organism. To mention other prominent examples, offense would be the core relational theme of anger and loss that of sadness. If, as Prinz wants, an instance of an emotion type, say a case of fear, represents its core relational theme, then we can understand what kind of survival advantages did emotions confer on our ancestors. Fear would then be a mechanism set up (by evolution) to detect dangers and act accordingly. We can now understand why emotions compel us to act in certain ways. For instance, it is most reasonable to fly away from an impending danger. So fear would be in place to promote behaviors which are appropriate responses to dangers.

Prinz's view is then that emotions represent core relational themes although they register bodily changes. Let us single out also this claim:

(A) Emotions register bodily changes but they represent core relational themes.

Why is it the case that there exist mental representations such that they register one thing and represent, however, quite another? Prinz's relies on his previous work about natural kind concepts in order to answer this question (2002). Consider the concept of dog. This concept applies correctly to something $X$ only if $X$ has a certain complex biological property, say, a certain genome. ${ }^{2}$ Yet, we humans do not have genome detectors. How does our concept then manage to track this biological property? Prinz's answer is that we actually register certain apparent properties of dogs (being four-legged, having fur, barking, etc.) which are actually caused by the genome in question. To the extent that there is some sort of reliable correlation between the appearances and the referent we may then develop concepts which track this referent simply by directly registering the

${ }^{1}$ To be precise, Lazarus distinguishes between anxiety and fright, but we can ignore this complication for the moment.

${ }^{2}$ This claim could be jeopardized in the light of recent developments in biology about the individuation of species. But this is of course an example and in place of a genome you can put the relevant biological property in question. In any case, I'm just following Prinz's own example here. 
relevant appearances. Prinz calls the appearances the nominal content of the concept and the referent its real content. So the real content of the concept $\operatorname{dog}$ is a certain genome, while its nominal content is a set of apparent properties of dogs which we use to track the genome in question. A similar story could be told for the concept water. The nominal content would in this case include apparent properties of water such as being liquid at certain temperatures, falling from the sky under certain atmospheric conditions, etc., and the real content would of course be the property of being $\mathrm{H}_{2} \mathrm{O}$. Now Prinz thinks that this account can also be applied to emotions. The idea is then that, for each emotion type, the real content is its core relational theme while the nominal content would be the relevant bodily changes. This is why he speaks of emotions as being "embodied appraisals", since they are supposed to represent relations that bear on the well-being of the organism by registering bodily changes. Emotions represent core relational themes by registering bodily changes: they track dangers, offenses or losses for the organism by feeling certain somatic changes.

Prinz's account of emotions is still incomplete, however. Emotions cannot just be embodied appraisals, since emotions have valence (they can be either positive or negative) and they are also conative states that motivate us to act. In fact, it can be argued that emotions are the strongest motivators for action. To account for valence and the conative role of emotions, Prinz introduces what he calls "valence markers". A valence marker is supposed to be a state with an imperative content, that is to say, a state with an intentional content such that in order to express it in language we should use the imperative mode. ${ }^{3}$ According to Prinz, there are two valence markers, one for positive emotions and another one for negative emotions. The positive marker involves a command to remain in the emotional state, so it has an imperative content that could be expressed linguistically as: "more of this!" By contrast, the negative marker has an imperative intentional content which can be expressed as: "less of this!", so it involves a command to bring the emotional state to an end. Hence a positive valence marker motivates us to maintain our present emotional state, while a negative marker motivates us to get rid of our present emotional state (Prinz 2004, ch. 7). Prinz's final view is then that an emotion is an embodied appraisal together with a valence marker. Let's also single out this last important claim:

\footnotetext{
${ }^{3}$ This notion is closely related to Millikan's notion of directive content, see Millikan 1995.
} 
(E) An emotion consists in an embodied appraisal jointly instantiated with a valence marker.

\section{Problems With Prinz's View}

In this section I will raise three problems or concerns with Prinz's view of emotions. Overall, they will target the three main claims of the view, $(\mathrm{J}),(\mathrm{A})$ and $(\mathrm{E})$.

\subsection{An Essential Tension}

The originality and interest of Prinz's view lies largely on its building into a basic Jamesian framework — claim (J) - some of the crucial insights of the cognitive tradition — claim (A) - . This is epitomized in the claim that emotions represent core relational themes by registering the bodily changes which actually cause them.

I wish to argue, however, that there exists a serious tension between claims (J) and (A). Let's go back to the registering / representing distinction and to the central claim that a core relational theme is the real content of an emotion type whereas its nominal content is a certain syndrome of bodily changes. The emotion is supposed to track a core relational theme by registering a certain syndrome of bodily changes (just as the dog concept tracks a certain genome by registering certain apparent properties of dogs). Given how the nominal / real content distinction is explicated this thesis can only be sustained if there is a reliable correlation between core relational themes and syndromes of bodily changes. Compare: the dog concept works only if the appearance properties of dogs through which we track the dog's genome are reliable indicators of the dog's genome; and this is supposed to be so since, in fact, these appearance properties are caused to be instantiated (in normal conditions) by the dog's genome.

Now take a basic emotion like fear. According to Prinz, there certainly exists a reliable correlation between the core relational theme of fear, danger, and a certain syndrome of bodily changes, at least in basic cases (which are supposed to be basic because all the rest of cases will be explained in terms of them, more on this later on). This correlation would have been set up by evolution:

Evolution has undoubtedly endowed us with distinctive physiological responses to various situations that our ancestors encountered. The heart is predisposed to race (along with several other physiological 
responses) when we see looming objects, snakes, crawling insects or shadows at night. (Prinz 2004, p. 69)

So the general idea is that snakes, crawling insects or shadows at night are what are called innate themes for fear ${ }^{4}$ and evolution has so designed our central nervous system, by way of the natural selection process, that when we perceive any of these themes then a whole syndrome of bodily changes - let us call them $\mathrm{BCH}_{\mathrm{F}}-$ follow. It is evolution then what guarantees that this syndrome of changes is a reliable indicator of any of these themes and a fortiori of danger.

So far so good, now the next question is: why has such a connection proven to be adaptive in the first place? The answer is that this syndrome of changes, $\mathrm{BCH}_{\mathrm{F}}$, is known to prepare the organism for an appropriate response to a danger or threat. A racing heart, for instance, enables us to run away. And it is of course highly adaptive to have been provided with a mechanism which enables us to escape when we are facing real dangers in our (evolutionary) environment. ${ }^{5}$

That would certainly explain why evolution has shaped a reliable correlation between certain prominent dangers for an organism and the changes $\mathrm{BCH}_{\mathrm{F}}$. Here is however where I think Prinz's theoretical construction runs into trouble. For, according to the Jamesian claim $(\mathrm{J})$, the crucial changes $\mathrm{BCH}_{\mathrm{F}}$ occur before and not after the emotion of fear. Actually, $\mathrm{BCH}_{\mathrm{F}}$ cause a state of fear on Prinz's account. So it follows that the syndrome of changes enabling an adequate response to danger $(=\mathrm{BCH} F)$ occurs before the organism has had the chance to instantiate a mental state representing danger $(=\mathrm{a}$ state of fear). Here we find what I think is an important tension in Prinz's understanding of emotions. It strikes me as very odd indeed to claim that an organism prepares itself to respond in an appropriate way to a certain challenge (for instance, a danger) before having any news about this challenge since it has not yet instantiated the corresponding emotion (in this case, fear) which is the mental state representing the challenge in question. So an organism prepares itself for a danger before being aware of any danger. theory.

${ }^{4}$ I borrow the terminology here from Ekman (2003) and the affect program

${ }^{5}$ What emerges from recent studies on the neurophysiological underpinnings of emotional reactions is that what is said to hold here for fear holds as well for the rest of basic emotions. So, in every case of a basic emotion, the subject typically undergoes a set of bodily changes which prepare her to perform a behavior in relation to the stimulus which is appropriate given a certain evaluation of it. See on this regard, Panksepp 1998. 
To see why this is problematic, recall that for Prinz a basic emotion like fear has an evolutionary origin. ${ }^{6}$ This was part of the argument that fear represents danger (for the organism) and not the syndrome of changes $\mathrm{BCH}_{\mathrm{F}}$. So it follows that fear was naturally selected. As it is well-known, however, traits in an organism are selected for what they cause to be, for some of their effects, and not for some of their causes. But the adaptive effect of fear can only be that of promoting behavior which is an adequate response to danger. In fact, as we saw above, Prinz himself thinks that fear was selected as a promoter of behavior appropriate for danger and that is part of the reason why, according to him, fear has the function of carrying information about danger, and hence it represents danger, and not the instantiation of $\mathrm{BCH}_{\mathrm{F}}$. Yet, considering the fact that the changes $\mathrm{BCH}_{\mathrm{F}}$ actually enable the organism to offer an adequate response to danger, the natural thought would be that fear was selected for promoting behavior adequate to dangers and that it does so precisely by causing the enabling changes $\mathrm{BCH}_{\mathrm{F}}$. But this is of course a natural move which is not open to Prinz's theory, since it would be incompatible with $(\mathrm{J})$. According to the characteristic Jamesian view, it is the enabling changes $\mathrm{BCH}_{\mathrm{F}}$ which cause the emotion of fear rather than the other way around. So Prinz's view is dragged to the odd claim that fear actually causes some behavior which is an appropriate response to dangers (that's why it was naturally selected) even if it does not cause the bodily changes which actually enable such a behavior. Quite the contrary, in fact these changes cause fear, according to $(\mathrm{J})$. So it seems that Prinz's account is putting the cart before the horses here.

I think that this points to a fundamental problem of Prinz's embodied appraisals theory. It is fundamental in the sense that it shows, it seems to me, that Prinz's clever way of incorporating a typical cognitive claim — claim (A) — into a basic Jamesian framework — claim

\footnotetext{
${ }^{6}$ Prinz seems now inclined to regard fear as a non-basic emotion (personal communication). This is, however, irrelevant for my argument. Prinz is still committed to an evolutionary explanation for the basic emotions, whatever they may turn out to be, and to the claim that all the rest of non-basic cases of emotions are to be derivatively explained from these basic ones (non-basic cases will be discussed presently). This is all that is required in order for the essential tension I'm discussing here to arise. Just substitute fear for an emotion truly regarded as basic. That basic emotion would consist in the perception of a certain syndrome of bodily changes and there should be again a reliable correlation between these changes and whatever core relational theme this basic emotion happens to represent. All the elements for the essential tension would then already be in place.
} 
(J) - is conceptually unstable. In order to argue that an emotion represents a core relational theme, a certain evaluation of the organism's environment, even though it is actually caused by the relevant bodily changes, Prinz has to appeal to an evolutionary origin for basic emotions and to an evolutionary explanation of why certain bodily changes are reliable indicators of certain core relational themes. These appeals, as I hope to have shown, drag his overall theory to claims which are extremely odd and implausible, namely, that an organism prepares itself to respond to danger before being aware of any danger and that fear causes behavior appropriate for dangers even though it does not cause, but it is actually caused by, the bodily changes enabling such behavior.

\subsection{The Explanation of Non-Basic Cases}

It is quite obvious that evolution cannot account for a reliable correlation between the instantiation of a core relation theme and a set of bodily changes in all instances of emotional reactions. This is not so even for basic emotions with an evolutionary origin like fear. We may react with fear to all kinds of dangers which are now salient in our actual environment - guns, job interviews, financial trouble, etc.which did not even exist in the environment in which our ancestors evolved. So Prinz needs to offer an account for all these non-basic cases. His main idea here is that in all these non-basic cases the crucial correlation between the instantiation of the core relational theme and the corresponding syndrome of bodily changes is established in virtue of certain mechanisms that rely on the evolutionary setup that accounts for the basic cases.

In Prinz's theory there are two non-basic cases to consider which involve different mechanisms or processes: one type of case occurs when a basic emotion like fear is elicited by a stimulus other than an innate theme; the other type of case concerns non-basic emotions. According to Prinz, there is only a limited pool of basic emotions and the rest are derived from the basic ones through two different mechanisms: blending and recalibration. For the purposes of this paper we need not concern us with this second type of case, non-basic emotions. Let us then concentrate only on the first case: the elicitation of a basic emotion by a stimulus which is not an innate theme.

Consider, to take one of Prinz's examples, being afraid of an exam. It is of course absurd to construe these cases as ones in which evolution has secured some causal link between the mental categorization of a situation as being an exam and the syndrome 
$\mathrm{BCH}_{\mathrm{F}}$ of bodily changes characteristic of fear. Prinz's suggestion here is that in all cases in which a core relational theme is instantiated by a stimulus which is not an innate theme of the emotion, the relevant bodily changes are causally mediated by a thought in which the corresponding axiological or evaluative concept is applied to the eliciting stimulus. For instance, in the case of fear, the thought "this (the exam) is dangerous (or threatening)" becomes a reliable cause of $\mathrm{BCH}_{\mathrm{F}}$ (which, in its turn, causes the state of fear) and it does so through a process of associative learning which draws on the basic cases of fear elicited by some of its innate themes.

Before examining the associative mechanism being suggested here, it is worth stressing that the existence of this cognitive causal process somehow attenuates the essential tension discussed above. What Prinz is saying is that in all cases in which something which is not an innate theme for fear triggers a fear response this is so because we happen to entertain a thought which applies the concept of danger to this something. So in all these non-basic cases, what causes the relevant bodily changes $\mathrm{BCH}_{\mathrm{F}}$ is a mental state which represents a danger. Therefore in all these cases, the changes follow from the organism's awareness of a danger. Still, as we are about to see, this is possible only because of an underlying associative mechanism that relies on the basic evolutionary setting, and moreover the mechanism itself, as I will argue, raises some concerns of its own.

Now Prinz does not spell out in detail how this learning mechanism is supposed to work, but he gestures at a possible "developmental sequence":

At some point, while experiencing fear in a darkened room, we entertain the verbally mediated thought that we are facing a dangerous situation. This happens on a number of subsequent occasions. At first, the thought "I'm in danger" is an effect of fear [...] But, through associate learning, that thought becomes a trigger for fear as well. Eventually, the explicit thought "I'm in danger" becomes capable of initiating fear responses in situations that lack the physical features that are predisposed to upset us as a function of biology. (2004, p. 76)

So the general idea is that at our early stages of development we experience states of fear as a result of frequent encounters with fear's innate themes (darkness, snakes, crawling insects). We then develop a concept of danger as a consequence of experiencing all these states. Our concept of danger emerges as a concept which is paradigmatically applied to the innate themes of fear and which is then supposed to 
"capture the features unifying" these themes (Prinz 2004, p. 76). As a result of this process, the concept of danger becomes strongly associated with experiences of fear in such a way that at some point the mere application of the concept to a stimulus which is utterly different in nature to any innate theme of fear becomes a triggering cause of an experience of fear.

A first problem with this account is that it makes a number of assumptions about how the concept of danger is acquired which should in any case be empirically confirmed (and the same goes, of course, for the other concepts involved in the rest of basic emotions - such as offense in the case of anger or loss in the case of sadness-). On the face of it, a number of questions spring to mind. Is it really required, in order to acquire the concept of danger, that young children experience relatively frequent cases of fear as a result of encounters with innate themes of fear? What if a young child is lucky enough not to encounter, or at least not frequently enough, such themes as snakes or shadows at night? Will she then not develop a concept of danger? Or will she then acquire a concept of danger which won't become associated with states of fear? Only future research in developmental psychology may help us to answer these questions in the way required by Prinz's theory.

A second problem concerns the claim that danger is developed as a concept which denotes the unifying features of the innate themes of fear. The worry here is that these themes are utterly different regarding their physical nature. Snakes and darkness, for instance, have little in common in this respect. Furthermore, there are perhaps countless ways of grouping together snakes and darkness, and the rest of innate themes of fear, but many of them will not group them together with guns or exams and the rest of learnt themes of fear. It would seem that innate themes of fear turn out to be too few for the reference of the concept of danger to be fixed by the property common to these innate themes. It is hard to see how a concept as complex and sophisticated as danger, an evaluative concept, gets its reference fixed upon such a meager basis.

\subsection{Valence Markers}

Consider now claim (E), an emotion consists in an embodied appraisal jointly instantiated with a valence marker. As we saw in the first section, the job of valence markers is to account for the valence of an emotion, its being positive or negative, and its conative or motivational role. Embodied appraisals are supposed to be states 
which track core relational themes by registering changes in the body. They are therefore doxastic states with a mind-to-world direction of fit. ${ }^{7}$ By contrast, a valence marker is supposed to be a mental state with an imperative content. Prinz thinks that there are two valence markers with the imperative content "More of this!" or "No more of this!" corresponding to a positive or negative valence respectively. Valence markers are then states with a world-to-mind direction of fit: "valence markers are internal commands to sustain or eliminate a somatic state by selecting an appropriate action" (Prinz 2004, p. 229).

Now Prinz's construal of emotion as a conjunction of two utterly distinct types of mental states faces the usual problem with such conjunctive theories: nothing in principle prevents one of the conjuncts from being instantiated in the absence of the other. In principle this is not bad. In some cases, an appraisal of a stimulus by a subject may not motivate her in the expected way. Consider for instance the case of the heavy smoker who judges her habit as being extremely dangerous for her health and yet she does not feel motivated to stop smoking. If only she were strongly motivated then quitting smoking would be much easier indeed! Prinz can explain cases like these as situations in which the relevant embodied appraisal is instantiated without the negative valence marker. ${ }^{8}$ There may be cases as well in which a state of fear is not negatively valenced. A possible example of this could be the case of people enjoying being terrified as they watch terror movies. Again, Prinz can explain these cases as situations in which an embodied appraisal of danger is jointly instantiated with a positive valence marker, instead of a negative marker. However, even if these cases may actually arise, it is important to recognize that they are exceptional if not outright odd. The norm should be that an appraisal of danger motivates us to avoid it, or do some other thing to appropriately deal with it, and makes us experience a negative feeling, especially so if we undergo the typical bodily changes of fear. Yet, if Prinz's theory were right, since embodied appraisals and valence

${ }^{7}$ For the notion of direction of fit see Anscombe 1957 and Searle 1983.

${ }^{8}$ In the case of the heavy smoker, it may be that she simply does not undergo any of the bodily changes $\mathrm{BCH}_{\mathrm{F}}$. In that case, Prinz's explanation should be that the thought "my smoking habit is dangerous" does not cause the changes $\mathrm{BCH}_{\mathrm{F}}$ and therefore the embodied appraisal is not instantiated either. This explanation raises problems of its own, however, since as we saw when discussing non-basic cases of emotion, Prinz thinks that applying the concept of danger actually causes the changes $\mathrm{BCH}_{\mathrm{F}}$ through a mechanism of associative learning. Prinz should then explain why, in spite of this associative mechanism being in place, at times the thought "I'm in danger" may not cause the changes $\mathrm{BCH}_{\mathrm{F}}$. But I will not push this concern further here. 
markers are completely independent mental states, without anything interesting in common (the former having indicative content and the latter imperative content), there is nothing in principle in Prinz's theory that prevents this sort of odd cases from being the norm rather than the exception. And this is surely an implausible consequence.

Still, one may on Prinz's behalf try to meet this objection by adding something to his theory that prevents this concern from arising. One natural suggestion here is that evolution has secured, by natural selection, that appraisals and valence markers get coinstantiated in the expected way: positive appraisals with the positive marker and negative appraisals with the negative marker. Appealing to evolution seems all the more natural in this context since, as we have seen, it already plays a crucial role in Prinz's account of basic emotions. Furthermore, since, for instance, negative valence ensures avoidance (or other forms of appropriate) behavior in response to something appraised as negative, surely such a conjunction would have survival value. ${ }^{9}$

There are, however, a number of problems with this suggestion. A first consideration is that if evolution had designed our brain in such a way that positive appraisals get paired with the positive marker, and negative appraisals with the negative marker, then we should expect them to co-occur in every circumstance. We would then have jumped out of the ashes and into the fire. Our initial problem was that Prinz's theory appeared too liberal, by allowing for all too many exceptions. Now we have designed a theory that seems to be too restrictive: it simply prohibits exceptions of any sort. Both options are wrong: exceptions are rare, but they exist nonetheless. A second problem with this suggestion is that it is hard to see how evolution could have secured the right sort of pairings between appraisals and valence markers, if Prinz's view on the appraisals involved in emotion is correct. In principle, negative appraisals should be conjoined with the negative marker, according to the suggestion we are considering, but it is unclear what subsumes all negative appraisals given Prinz's theory. Recall that for Prinz appraisals are embodied, they are states that register bodily changes which are correlated with the instantiation of a core relational theme. Different negative appraisals actually register completely different syndromes of bodily changes (think for instance of typical changes involved in anger or sadness). What seems to unite negative appraisals is the negative character of the core relational theme that they represent, but it is hard to see how

${ }^{9}$ I am grateful to an anonymous referee of Crítica for suggesting this possibility. 
this feature can be factored in an evolutionary mechanism leading to the sort of design suggested.

These two considerations may not be unsurmountable, but they would surely require working out a more complicated addition to Prinz's theory, and one that is by no means innocuous, as it would involve certain substantial claims. Thus, in response to the first concern, one might perhaps suggest that evolution has secured a causal mechanism by which a negative appraisal causes the negative marker to activate (and mutatis mutandis, for positive appraisals). Since it is a causal mechanism, it may be disrupted when abnormal conditions occur, and this may well account for exceptions in which appraisals are followed by the wrong marker or they are not followed by any marker at all. In this way, one could make a principled case for distinguishing between normal cases and exceptions, as the available data requires. So far, so good; yet, this addition to Prinz's theory would commit him, however, to the view that emotions are causal processes with two stages, an embodied appraisal and a valence marker, a view which would then render Prinz's theory relevantly similar to the alternative that I will suggest later on, the multidimensional appraisal theory of emotion. When discussing this further theory at the beginning of the fourth section, therefore, I will take up this issue again. The second concern, on the other hand, seems harder to meet, and the only possibility I can think of, consistent with Prinz's theory, is that evolution has set up a causal mechanism for each type of appraisal. So evolution would have secured that whenever the embodied appraisal involved in fear gets activated this causes the activation of the negative marker, and in addition to this that whenever the embodied appraisal involved in anger gets activated this causes the activation of the same negative marker, and so on for the rest of negative emotions. We seem then to be required to postulate several different causal mechanisms shaped by evolution, one for each emotion type. So there would not be one single mechanism linking, for instance, negative appraisals with the negative marker.

We have then raised three problems for Prinz's perceptual view of emotion. I do not think that any of them are knock-down arguments against it, but I think they show potential weaknesses or points at which the account seems to run into trouble or at the very least needs substantial development and much more argument. In the two remaining sections of this paper I will present an alternative account of emotions, the (multidimensional) appraisal theory, and I will argue that it is, on the one hand, free from the three worries raised and, on the other hand, that it can accommodate the Jamesian arguments 
that motivated Prinz's account in the first place. If this is correct, then I think we would have good reason to prefer the alternative appraisal theory to Prinz's account.

\section{Appraisal Theories of Emotion}

Appraisal theories constitute one of the main approaches to emotion in contemporary psychology. Although they can be traced back to the ancient Stoics, psychologists often mention the work of Magda Arnold as the seminal source of the view (1960). The leading idea is that the emotion undergone by an organism depends crucially on how the organism interprets the stimulus, or object of the emotion, rather than on the nature of the stimulus. This is supposed to explain wellknown facts about emotions, namely, that the same stimulus may elicit different emotions in different subjects, or even in the same subject at different times, and that a stimulus may or may not elicit an emotion depending on the organism facing it. The explanation of all these facts will be the same: what determines the emotional response is not the stimulus per se but how the emoter interprets or appraises the stimulus.

Prinz treats appraisal theories in psychology as belonging to the same class, for the purposes of his main argument in Gut Reactions, as judgmentalist theories defended by philosophers such as Robert Solomon or Martha Nussbaum. This move assumes that appraisals are some sort of cognitive states involving the deployment of axiological or evaluative concepts. Although Richard Lazarus, probably the most influential appraisal theorist among contemporary psychologists, can perhaps be interpreted as espousing such a view, the fact is that some of the current appraisal theorists do not follow him in this respect (see for instance Scherer 2009). This will be of importance later on.

One other aspect which is present in most versions of the appraisal theory and is also crucially different from such theories as Solomon's and Nussbaum's is that emotions are taken to be causal processes rather than simple states. They would consist of different causally related stages which unfold following a fixed temporal sequence. So, strictly speaking, we should refer to emotional responses as emotional episodes rather than emotional states. According to this view, an emotional episode is triggered by the organism's appraisal of the stimulus. ${ }^{10}$ Following Lazarus, current versions of this theory hold that this

\footnotetext{
${ }^{10}$ There is a characteristic hesitation among appraisal theorists on whether to count this appraisal as the initial component of the emotional episode or rather as its (normal) triggering cause. For reasons I will partially reveal at the end of the
} 
appraisal is itself a process which involves the evaluation of the stimulus along a series of parameters or appraisal dimensions. This is why the general view is sometimes referred to as "multidimensional" appraisal theory. Versions of this general view differ as to exactly which and how many dimensions to count in (see Scherer et al. 2001 for a survey of appraisal theories). By way of illustration, suffice it to say that most of them typically include as appraisal dimensions the following: goal relevance (whether the stimulus, or an aspect of it, bears on some goal or need of the organism); goal congruence (whether the stimulus helps to promote some goal or need or rather obstructs it); coping potential (an estimation of the capacity by the organism either to cope with the challenge posed by the stimulus when it is goal incongruent or to take the chance offered by it when it is goal congruent). According to some models, these appraisal dimensions are then processed sequentially. This is all the more reasonable, since some appraisal dimensions seem to require the result of others in order to start on. For instance, an estimation of the coping potential seems to require an output result for the dimension of goal congruence.

The upshot of this appraisal process is the bringing about of a set of characteristic effects or responses. Most models count among them physiological responses (for instance, changes in the endocrine system, and more generally changes governed by the Autonomic Nervous System-ANS), motor expressions (for instance, facial expressions, or vocal and musculo-skeletical changes) and action tendencies (a mental state of readiness to perform a piece of behavior, for instance, a tendency to approach or withdraw from the stimulus). This array of effects is supposed to occur more or less at the same time and together constitute the second main stage in the emotional process or episode. Appraisal theorists refer to this set of changes as the response stage or component of the emotional episode.

This second stage causes in its turn the third one, which would consist in a phenomenological representation of most of the elements involved in the previous stages. ${ }^{11}$ This is the so called feeling component of the emotional episode, according to these models. The function attributed to this stage ranges from being required for the purposes of communication to being a monitoring device of the whole process which improves its accuracy, efficiency and flexibility. Some

paper, I think the first option is better than the second. But nothing of consequence follows from this for the purposes of this paper.

${ }^{11}$ According to some models, however, not all elements represented need to be consciously represented (see for instance Scherer 2004). On this issue, see the later part of the paper. 
models mention also that the modification or suppression of certain emotional behaviors (which might be due to some personal strategic reason or to social norms and pressures) also requires that most elements of the emotional episode be phenomenologically represented by the mind. The important thing to bear in mind for our purposes about the feeling component of emotion is that it is responsible for the conscious character of an emotion. The claim is that a subject will be phenomenally conscious of an emotional episode she is undergoing only when it reaches this final stage and only to the extent that it reaches it. Finally, some models add also a fourth final stage of verbalization, but we do not need to consider it here.

To sum up, according to the (multidimensional) appraisal theory an emotion is not a single mental state (or, for that matter, a conjunction of two mental states) but it is rather a causal process involving different components or stages, some of them mental some of them non-mental. These three stages are causally linked, with the appraisal component shaping the rest of the process, and the response and feeling components occurring as a causal consequence of appraisal.

\section{Appraisal Theories and The Jamesian Arguments}

Prinz thinks that the three Jamesian arguments discussed in the first section require us to accept the central Jamesian claim (J). The main purpose of this final section is to show that this is not correct since the appraisal theory, an alternative account of emotion which is not committed to $(\mathrm{J})$, can adequately address these three Jamesian considerations.

Before going into this, however, it may be useful to briefly notice that the appraisal theory does not fall prey of the three worries that I raised against Prinz's account in section two. It is clear that the first two worries do not concern the appraisal theory. The first one does not arise because the appraisal theory is not committed to $(\mathrm{J})$. According to the appraisal theorist, the typical bodily changes of an emotional episode always follow the appraisal of the stimulus whenever this appraisal triggers the emotional episode. With respect to the second concern, the appraisal theorist does not need to postulate an associative mechanism in order to account for our concept of danger, since again she is not committed to $(\mathrm{J})$ and does not regard cases in which bodily changes follow from a cognitive evaluation of the stimulus as dependent on cases where they do not.

The third concern, the explanation of valence and the motivational role of emotion, does indeed apply to the appraisal theory as well: 
any theory of emotion should explain valence and the conative aspect of emotion. So let us see how the appraisal theory addresses this worry. First, the motivational role of emotion relies on action tendencies. As we saw, action tendencies are supposed to be part of the response component of an emotional episode. They are mental states of readiness to perform a specific piece of behavior. Therefore, they are mental states with the appropriate world-to-mind direction of fit.

Second, since action tendencies (like the rest of elements integrating the response component) are causal effects of the appraisals featuring in the appraisal stage of the emotional episode they are to some extent dependent on them. This prevents the account from facing the sort of worry I raised for Prinz's account. Recall that the worry was that since, on Prinz's account, the embodied appraisal and the valence marker are independent mental states, in principle they can be instantiated independently the one from the other. On the appraisal account, by contrast, the action tendency is caused by the appraisal, so we should expect the former to follow from the latter at least in normal cases. There might be abnormal cases in which the response stage gets activated without an appraisal (more on this later, when we discuss cases of direct physical induction of emotion) or cases where the appraisal does not cause the relevant response component to get activated (this might be the case of the heavy smoker discussed earlier or what goes on in cases of "positive fear"), but on the appraisal theory these cases remain as exceptional, as I think they should be.

Finally, with regard to valence, the appraisal theorist usually explains it in terms of the output of the appraisal dimension of goal congruence. A positive emotion arises when the stimulus is appraised as being goal congruent, whereas a negative emotion occurs when the stimulus is appraised as goal incongruent.

As we saw when discussing Prinz's theory, the available data to the effect that appraisals, valence and conative role tend to go together albeit they admit also of exceptional cases, suggests that these elements are structured causally. This is exactly what the appraisal theory proposes as it conceives of emotion as a causal process involving these elements as stages or components. As we saw at the end of the second section, Prinz's theory would seem to require some amendment along these lines as well, and for the same reason. On the other hand, we also remarked, when discussing Prinz's theory, that one problem the theory faces is to explain what unifies the 
appraisals involved in, for instance, positive emotions so as to get paired with the right conative state. Again, this problem does not arise in the sort of appraisal theory I'm defending here, since the conative state - the action tendency - is caused by a certain appraisal - goal-congruence - which would in fact subsume all those so-to-speak positive appraisals (goal-incongruence subsuming all negative appraisals). So we would not need to postulate several causal mechanisms to account for the expected pairings between appraisals, valence and conative role in emotional episodes; a single causal mechanism may underlie all of these pairings if an emotion is structured as defended by the appraisal theory.

Let us then now examine Prinz's three reasons for holding the Jamesian central claim (J). I will conclude this paper by arguing that they can all be conveniently addressed by the appraisal theory. If this is correct, we will then have no good reason to hold onto $(\mathrm{J})$ and, given the three worries raised for Prinz's perceptual theory, my final conclusion will be that overall the appraisal theory offers a better understanding of the nature of emotion than Prinz's view.

\subsection{James' Subtraction Argument}

The first reason is James' subtraction argument. The argument runs as an inference to the best explanation of the fact that the phenomenology of an emotional episode is exhausted by feelings of bodily changes. As we saw, James used a thought experiment to establish the crucial fact in question, but we mentioned also some empirical evidence that seems to support it too.

There are two possible ways to undermine this argument. First, one can challenge the supposed established fact; second, one can challenge the inference from this fact to claim $(\mathrm{J})$. I think the second option is better, but let me start by briefly considering the first one, as it introduces a matter of concern which is good to mention. Advocates of the existence of cognitive phenomenology claim that there is something it is like to think that something is the case (Pitt 2004). Some of them have applied this general view onto the specific case of emotion. Thus, according to some thinkers, the phenomenology of a sadness episode includes not just feelings of bodily changes but also, among other things, an experience of loss (Goldie 2002; Kriegel 2011). If they were correct, then one could not infer (J) as an inference to the best explanation from the phenomenology of emotion, since emotion would include some distinctive cognitive phenomenology as well. Prinz has of course denied that there ex- 
ists some distinctive cognitive phenomenology. According to him, all phenomenology is sensory phenomenology and, therefore, the phenomenology of emotion is exhausted by feelings of bodily changes (Prinz 2012)

The claim that there exists a distinctive cognitive phenomenology remains controversial. Therefore, an objection to the subtraction argument resting on it may appear as not being powerful enough. Things are different, however, with regard to the second possible objection. Let us then endorse, for the purposes of the argument, that Jamesians are right when they hold that the phenomenology of emotion is exhausted by feelings of bodily changes. The second premise of the subtraction argument is that $(\mathrm{J})$ offers the best explanation for this phenomenological fact. As it is well known, this type of premise in an abductive argument can be challenged if another possible explanation for the same fact can be offered which looks at least as good. I do think that the appraisal theory provides us with such an alternative. As we have seen in the preceding section, according to the appraisal theory the phenomenology of emotion emerges when the complex causal process, the emotional episode, reaches the so-called feeling stage or component. This means that a subject undergoing an emotion becomes phenomenally conscious of the whole process only when the process reaches this third stage. Moreover, the subject is phenomenally conscious only of those elements and components of the process which are phenomenologically represented at this stage. If these elements typically include bodily changes, that may well explain empirical data suggesting that when subjects report feeling an emotion (that is to say, when they become phenomenally conscious of it) areas of the brain whose job is to build maps of the body are activated (see Damasio et al. 2000). In fact, the appraisal theory remains neutral regarding the controversy about cognitive phenomenology. If the Jamesian is right in this regard, then it will follow that the phenomenological state of an emotional episode represents only the elements of the response component, the bodily changes (leaving probably aside action tendencies), and this will then be perfectly consistent with the claim that the phenomenology of emotion is exhausted by the phenomenology of bodily feelings. In sum, then, the appraisal theory offers a good theoretical alternative for explaining the phenomenology of emotion, and the inference from this phenomenology to claim $(\mathrm{J})$ seems therefore ungrounded. 


\subsection{Cognition And Emotion Involve Two Separate \\ Neuroanatomical Structures}

Let's then move on to the second Jamesian reason. Prinz backs Robert Zajonc in his dispute with Richard Lazarus and endorses the claim that emotion and cognition involve two distinct neuroanatomical structures. Prinz, as Zajone did, infers from this that emotion does not involve appraisal. One difficulty with evaluating this argument is that it relies on the elusive notion of cognition, which has revealed hard to spell out. In his book, after a long discussion of supposedly failed attempts of elucidation, Prinz offers his own definition of cognition: a cognitive state or process is one which exploits representations that are under organismic control rather than under the control of the environment. A representation is under organismic control when "the organism has activated it or maintains it in working memory", in short, when "is residing in memory or has been activated from memory" (see Prinz 2004, pp. 45-46). According to this definition, perceptual states are not cognitive states, but percepts may become cognitive when stored in memory and activated from memory. Prinz makes clear, however, that his view of the cognitive is rather dispositional:

you see a dog and form the thought that there is a dog in front of you. This thought, and its constituent concepts, does not occur as a result of organismic control. It is a reflex-like response to your experience. It qualifies as a thought because the representations it contains are under organismic control in a dispositional sense. You can willfully form thoughts using your dog concept. ${ }^{12}$

Now, the first thing to notice in connection with this argument is that appraisal theorists want of course to attribute to non-human animals and new-born infants the capacity to emote. And furthermore they think that the human emotional system has an evolutionary origin, that it was naturally selected as a way of discerning in the environment matters of importance for the organism and of helping it to deal with them in appropriate ways. Given all this, they think that some of our emotional responses are pre-wired or automated, reflex-like, to use Prinz's locution. In fact, Magda Arnold defined appraisal as "direct, immediate, intuitive" (see 1960, p. 173).

Following this thread, according to some appraisal theorists there would be three mechanisms which can trigger an emotional episode.

${ }^{12}$ See Prinz 2004, pp. 45-46, emphasis belongs to the original. 
First, an innate process would automatically elicit a certain appraisal pattern (a set of outputs in the different appraisal dimensions) whenever certain stimuli (the innate elicitors of emotion) are perceived. This mechanism may account for what goes on in cases such as LeDoux's, and would have been shaped by evolution. Second, an associative process would allow building an association between perception of certain stimuli and certain appraisal patterns, probably as a result of frequent or extremely intense emotional episodes or some other strong reinforcers (like cultural or social influence). The result will be that the appraisal pattern gets activated automatically whenever the subject encounters again the relevant stimulus. This mechanism would be particularly important in early childhood but can operate in adult life as well. Finally, there would be a third mechanism where the appraisal pattern is obtained after a conscious and deliberate evaluation of the stimulus (as when one experiences fear after deducing that an intruder has broken into the house) (see Leventhal and Scherer 1987; Smith and Kirby 2011).

Now, although it is difficult to tell given the elusiveness of Prinz's dispositional conception of the cognitive, it seems clear enough that appraisals which result from the first process (and perhaps also those arising out of the second as well) would not count as cognitive states according to Prinz's definition. What is more important, the postulation of these three mechanisms is not a matter of simple theoretical speculation. Recent empirical evidence is emerging now suggesting that appraisals may occur in an automated way. For instance, in one study, subjects where trained in a game in which producing certain colors lead to positive rewards while producing certain others lead to losses. In this way, certain colors were regarded by subjects as being goal congruent and others as goal incongruent. After that, in a series of trials they were presented with samples of colors for a very short period of time $(200 \mathrm{~ms})$ and after a pause of $100 \mathrm{~ms}$ they were shown a target stimulus which could be a positive word (e.g., "happy") or a negative word (e.g. "cruel"). The subjects were required to respond whether the target words where positive or negative. It was found that subjects responded much faster and with less errors when the prime stimulus, the color, and the target stimulus, the word, were appraisal congruent (for instance, a goal-congruent stimulus with a positive word, or a goal-incongruent stimulus with a negative word). The very short pause between the prime and target stimulus had a masking effect on the prime stimulus. This fact together with the very fast responses given by the subjects gives reason to think that 
they processed in each trial the goal-congruence of the colors, a typical appraisal dimension according to the appraisal theory, in an automated fashion. Similar studies suggest cases of automatic processing of the coping potential dimension (see Moors 2010).

Finally, and perhaps more importantly, more recent studies on the neurophysiological underpinnings of emotional episodes suggest that appraisal states, on the one hand, and typical emotional responses, on the other, far from being neuroanatomically separated, as Zajonc argued, appear to be neuroanatomically and neurophysiologically integrated. As regards neuroanatomical integration, new evidence is now emerging that the amygdala, a critical subcortical structure monitoring the bodily changes typical of fear and other emotional episodes, as LeDoux's studies have shown, seems to be crucial as well for the processing of appraisal information typical of the goal relevance dimension (Sander, Grafman and Zalla 2003). As regards neurophysiological integration, according to recent studies, hypothesized brain circuits for emotional episodes would form recursive networks with frequent feedback loops. According to these models, brain areas mainly involved in the appraisal component, which in principle send forward information to areas devoted to the response component, are also actually influenced by these latter areas by way of this feedback process. Therefore, appraisal areas and response areas modulate their activity as a result of this interaction (Lewis 2005).

\subsection{Direct Physical Induction of Emotion}

It remains only to be considered the last reason afforded by Prinz for thinking that bodily changes precede emotion. This is the alleged existence of cases of direct physical induction of emotion. Administering certain drugs or even adopting certain characteristic facial expressions is told to provoke an emotional response. Of course this is on the face of it a fact which seems more easily explained by Prinz's theory than by appraisal theories. Indeed a plausible explanation of what goes on in these cases is that drugs directly cause the bodily changes the registration of which, according to Prinz, constitutes the emotion.

It is interesting to note that most appraisal theorists claim that this sort of cases is not covered by the theory. This is in fact the chief reason why they tend to speak of appraisals as being the usual cause of an emotional episode rather than its first and triggering component. The idea is that appraisals are the usual way in which 
emotional episodes arise, but there would also be the alternative way of direct physical induction.

I think on the contrary that this reaction may be too quick and that it actually underestimates the resources available to appraisal theories. I will conclude then by suggesting some ways in which cases of physical induction can be accounted for within the appraisal theory. My aim here is not primarily to argue for any of these ways, the point is rather that there isn't any need to drop the claim that appraisal is the initial triggering component of an emotional episode, at least as far as cases of direct physical induction are concerned.

A first suggestion is this. According to the appraisal theory, an emotion is a causal process consisting of three main stages: the appraisal, the response and the phenomenological components. Now perhaps what goes on in cases of direct physical induction is that the physical inductor causes a typical pattern of activity in brain centers responsible for the response component of a certain type of emotional episode. This in turn causes the activation of centers issuing a phenomenological representation of these responses. Thus in cases of physical induction we may well end up with a process starting with a response component and following through with a feeling component. That is to say, in cases like this we will have a typical emotional episode minus its initial appraisal stage. We will then only have a segment of the normal emotional episode. Although these segments should not be considered full-fledged emotions given that they lack of the initial appraisal component, they still have a lot in common with them. Moreover, assuming as correct the Jamesian remark that the phenomenology of an emotional episode is exhausted by feelings of bodily changes, there would be little difference, from a phenomenological perspective, between these segments and fullfledged emotions. That is to say, the subject would experience the same sort of changes and would be in a phenomenally conscious state very similar to that arising from a full-fledged emotional episode. This last fact will then make it the more reasonable to mistake these segments for genuine emotions and may account for the sort of empirical evidence adduced by Jamesians in this regard.

A second consideration allows us however to go a bit further. The objection seems to assume that physical induction (e.g. the ingestion of certain drugs) cannot alter or bias the workings of the appraisal system of the organism. But this assumption can be challenged. Little is yet known about mental architecture as implemented by the human brain. But some of the best known processes (for instance, vision) 
show that the brain uses recurrent networks. In recurrent networks information does not travel in one direction only; it does not proceed always forward till the last stage of processing is reached. Instead the output of a certain stage of the process feeds back and influences the output of a previous stage which is processed again and again until the general process stops (Damasio 2010, chapter 3). As was remarked in the previous subsection, some affective neuroscientists favor this sort of architecture in the case of the processing of emotion. According to some models, appraisal brain centers and response brain centers are connected by recurrent networks featuring feedback loops. If this is indeed so, then it can well be the case that when certain response effects, typical of an emotional episode, are brought about by direct physical induction, then they activate brain areas responsible of the appraisal component in virtue of this recurrent circuitry. The end result may then well be an overall pattern of activation in the brain closely resembling that of a standard fullfledged emotional episode. ${ }^{13}$

\section{REFERENCES}

Anscombe, G.E.M., 1957, Intention, Blackwell, Oxford.

Arnold, M., 1960, Emotion and Personality, Columbia University Press, New York.

Damasio, A., 2010, Self Comes to Mind. Constructing the Conscious Brain, William Heinemann, London.

Damasio, A.R., T.J. Grabowski, A. Bechara, H. Damasio, L.L.B. Ponto, J. Parvitzi, and R.D. Hichwa, 2000, "Subcortical and Cortical Brain Activity During The Feeling Of Self-Generated Emotions", Nature Neuroscience, vol. 3, no. 10, pp. 1049-1056.

Ekman, P., 2003, Emotions Revealed. Recognizing Faces and Feelings to Improve Communication and Emotional Life, Henry Holt and Company, New York.

Ellsworth, P. and K.R. Scherer, 2003, "Appraisal Processes in Emotion", in R. Davidson, K. Scherer, and H. Goldsmith (eds.), Handbook of Affective Sciences, Oxford University Press, Oxford, pp. 572-595.

${ }^{13}$ Research leading to this work has been partially funded by the Spanish Ministry of Economy and Competitiveness, research grants FFI2010-15717 and FFI201237354. Previous versions of this work were read at the XXII SIUCC held in San Sebastian in September 2012, at the Ontology of Emotions conference held in Geneva in April 2013 and at the Logos Seminar in Barcelona in December 2013. I thank the audiences there for helpful comments and suggestions. I'm also indebted to two anonymous referees of Crítica for their comments and criticisms to a previous draft. Finally, my special thanks to Jesse Prinz for personal discussion of some of the issues raised in this work. 
Frijda, N., 2007, The Laws of Emotion, Lawrence Erlbaum, New Jersey. , 1986, The Emotions, Cambridge University Press, New York.

Goldie, P., 2002, "Emotions, Feelings and Intentionality", Phenomenology and the Cognitive Sciences, vol. 1, no. 3, pp. 235-254.

James, W., 1884, “What Is An Emotion?", Mind, vol. 9, no. 34, pp. 188205.

Kriegel, U., 2011, "Towards a New Feeling Theory of Emotion", European Journal of Philosophy, vol. 22, no. 3, pp. 420-442.

Lazarus, R., 1991, Emotion and Adaptation, Oxford University Press, New York

LeDoux, J., 1996, The Emotional Brain, Simon and Schuster, New York.

Leventhal, H. and K. Scherer, 1987, "The Relationship of Emotion to Cognition: A Functional Approach to a Semantic Controversy", Cognition and Emotion, vol. 1, no. 1, pp. 3-28.

Lewis, M.D., 2005, "Bridging Emotion Theory and Neurobiology through Dynamic Systems Modeling", Behavioral and Brain Sciences, vol. 28, no. 2, pp. 169-245.

Millikan, R., 1995, "Pushmi Pullyu Representations", in J. Tomberlin (ed.), Philosophical Perspectives, vol. 9, pp. 185-200.

Moors, A., 2010, "Automatic Constructive Appraisal as a Candidate Cause of Emotion", Emotion Review, vol. 2, no. 2, pp. 139-156.

Nussbaum, M., 2001, Upheavals of Thought. The Intelligence of the Emotions, Cambridge University Press, New York,

Panksepp, J., 1998, Affective Neuroscience. The Foundations of Human and Animal Emotion, Oxford University Press, New York.

Pitt, D., 2004, "The Phenomenology of Cognition; or What is it Like to Think that P", Philosophy and Phenomenological Research, vol. 69, no. 1, pp. 1-36.

Prinz, J., 2012, The Conscious Brain, Oxford University Press, New York. , 2008, "Précis of Gut Reactions", Philosophy and Phenomenological Research, vol. 76, no. 3, pp. 707-711.

- 2007, The Emotional Construction of Morals, Oxford University Press, New York.

- 2004, Gut Reactions. A Perceptual Theory of Emotion, Oxford University Press, New York.

- 2002, Furnishing the Mind: Concepts and their Perceptual Basis, MIT Press, London.

Sander, D., J. Grafman, and T. Zalla, 2003, “The Human Amygdala: An Evolved System for Relevance Detection", Reviews in the Neurosciences, vol. 14, no. 4, pp. 303-316.

Searle, J., 1983, Intentionality, Cambridge University Press, New York.

Scheier, M.F. and C.S. Carver, 1985, "Optimism, Coping, and Health: Assessment and Implications of Generalized Outcome Expectancies", Health Psychology, vol. 4, no. 3, pp. 219-247. 
Scherer, K.R., 2009, “The Dynamic Architecture of Emotion: Evidence for the Component Process Model", Cognition and Emotion, vol. 23, pp. 1307-1351.

— , 2004, "Feelings Integrate the Central Representation of AppraisalDriven Response Organization in Emotion", in A. Manstead, N. Frijda, and A. Fischer (eds.), Feelings and Emotions: The Amsterdam Symposium, Cambridge University Press, New York, pp. 136-157.

— , 2001, "Appraisal Considered as a Process of Multilevel Sequential Checking", in Scherer et al. (eds.), 2001, pp. 92-120.

Scherer. K.R., A. Schorr, and T. Johnstone (eds.), 2001, Appraisal Processes in Emotion: Theory, Methods, Research, Oxford University Press, New York.

Smith, C.A., and L.D. Kirby, 2001, "Toward Delivering on the Promise of Appraisal Theory", in Scherer et al. (eds.), 2001, pp. 121-138.

Solomon, R.C., 2003, Not Passion's Slave, Oxford University Press, New York.

—_ 1976, The Passions, Doubleday, New York.

Van Reekum, C.M. and K.M. Scherer, 1997, "Levels of Processing in Emotion-Antecedent Appraisal", in G. Matthews (ed.), Cognitive Science Perspectives on Personality and Emotion, Elsevier Science, North Holland, Amsterdam, pp. 259-300.

Zajonc, R., S. Murphy, M. Inglehart, 1989, "Feeling and Facial Efference: Implications of the Vascular Theory of Emotion", Psychological Review, vol. 96, no. 3, pp. 395-416.

Received: May 9, 2014; revised: October 14, 2014; accepted: January 14, 2015. 